AECENES

ORNL/M-4629

FEB 211998

OSTI

\title{
Summary of Dynamic Analyses of the Advanced Neutron Source Reactor Inner Control Rods
}

\author{
W. R. Hendrich
}

August 1995

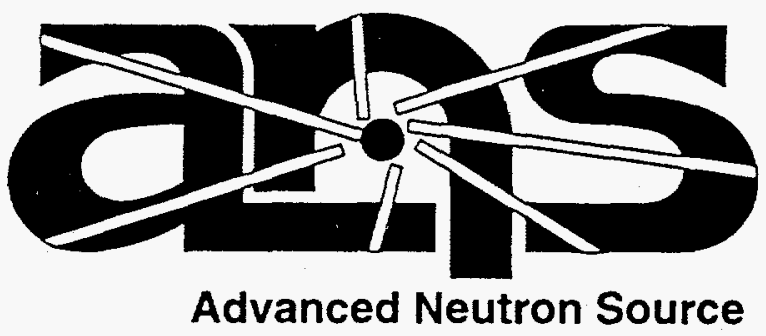


This report has ben reproduced directly from the best availabie copy.

Available to DOE and DOE contractors from the Office of Scientific and Technical Information, P.O. Box 62, Oak Ridge, TN 37831; prices available from (615) 576-8401, FTS 626-8401.

Available to the public from the National Tochnical information Service. U.S. Department of Commerce, 5285 Port Royal Rd., Springfield; VA 22161.

This report was prepared as an account of work sponsored by an agency of the United States Government. Neither the United States Government nor any agency thereof, nor any of their employees, makes any warranty, express or implied, or assumes any legal liability or responsibility for the accuracy, completeness, or usefulness of any information, apparatus, product, or process disclosed, or represents that its use would not intringe privately owned rights. Reference herein to any specific commercial product, process, or service by trade neme, trademark, manufacturer, or otherwise, does not necessarily constitute or imply its endorsement, recommendation, of favoring by the United States Government or any egency thereof. The views and opinions of authors expressed herein do not necessarily state or reflect those of the United States Government or any agency therect. 
Engineering Technology Division

\section{SUMMARY OF DYNAMIC ANALYSES OF THE ADVANCED NEUTRON SOURCE REACTOR INNER CONTROL RODS}

W. R. Hendrich

August 1995

Prepared by the OAK RIDGE NATIONAL LABORATORY

Oak Ridge, Tennessee 37831 managed by

LOCKHEED MARTIN ENERGY SYSTEMS, INC.

for the

U.S. DEPARTMENT OF ENERGY

under contract DE-AC05-84OR21400 
CONTENTS

ABSTRACT $\ldots \ldots \ldots \ldots \ldots \ldots \ldots \ldots \ldots \ldots \ldots \ldots \ldots \ldots \ldots \ldots \ldots \ldots \ldots$

1. INTRODUCTION $\ldots \ldots \ldots \ldots \ldots \ldots \ldots \ldots \ldots \ldots \ldots \ldots \ldots \ldots \ldots \ldots \ldots$

2. FLOW-INDUCED VIBRATIONS $\ldots \ldots \ldots \ldots \ldots \ldots \ldots \ldots \ldots \ldots \ldots \ldots$

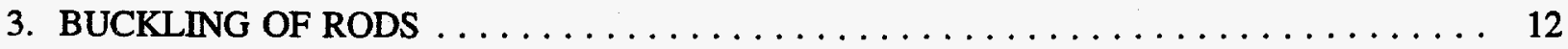

4. SCRAM PERFORMANCE $\ldots \ldots \ldots \ldots \ldots \ldots \ldots \ldots \ldots \ldots \ldots \ldots \ldots$

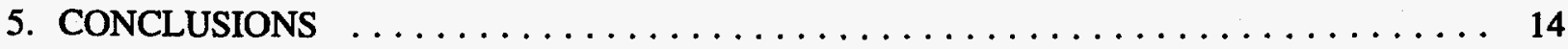

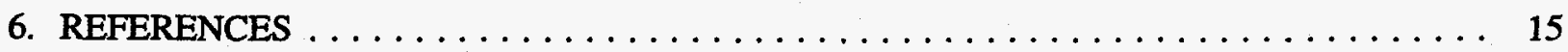




.




\section{ABSTRACT}

A summary of the structural dynamic analyses that were instrumental in providing design guidance to the Advanced Neutron Source (ANS) inner control element system is presented in this report. The structural analyses and the functional constraints that required certain performance parameters were combined to shape and guide the design effort toward a prediction of successful and reliable control and scram operation to be provided by these inner control rods.

\section{INTRODUCTION}

The primary objective of the Advanced Neutron Source (ANS) was to produce the world's most intense source of continuous thermal and subthermal neutrons for use in fundamental physics and nuclear physics research. To achieve a high neutron density, relatively constant during the cycle, outside the core where the neutron beam tubes could be located, the hafnium control elements were placed inside the inner annulus of the core as illustrated in Fig. 1. In this small (190-mm-diam) inner cylinder, the control rod system was subjected to an axial flow of coolant $\left(\mathrm{D}_{2} \mathrm{O}\right)$ at relatively high velocities: the expected velocity varied in the range of 4 to $10 \mathrm{~m} / \mathrm{s}$ as the design evolved through several iterations. Figure 2 shows the two-element core configuration from the early phases of the conceptual design on which much of the flow-induced vibration (FIV) studies were based. The unsupported length-to-diameter ratio $(1 / d \cong 60)$ of the inner control elements was much greater than normally encountered in commercial or experimental reactors. Consequently, early in the ANS conceptual design phase, the concern for FIVs was highlighted, and serious efforts were undertaken to understand the axial flow effects and to find a design that avoided problems while giving a minimal impact on control element functionality. This document provides a record of the design experience gained while addressing the FIV issue so that this experience can be applied to similar axial flow problems.

Flow-induced vibration was found to be influenced by the scram requirements, which also had the potential to create a structural buckling condition during the deceleration phase of the scram. Constraints of any kind on the portion of the control rods that moved during scram had the potential to degrade the scram performance. Yet the best way to avoid FIV was to provide lateral constraints on the rods to minimize the lateral response by increasing the fundamental lateral bending frequency of the control element system. As the design progressed, changes were made to provide flexible lateral constraints that would greatly reduce the FIV problem and at the same time not create any binding or friction that could degrade the scram performance. In addition, the length-to-diameter ratio was reduced by increasing the diameter and reducing the length through major mechanical design changes while maintaining the same functional capabilities. The diameter was increased by using three larger rods rather than four rods as in the preconceptual design phase. The length was reduced by rearranging the scram spring configuration.

Lateral constraints were provided to the control rods by a system of spring-mounted rollers that minimized the possibility of scram performance degradation. To prevent wear between the rollers and the hafnium, the hafnium was encased in an outer cylinder. Several sets of materials were studied to achieve good wear. An attempt was also made to maximize the ratio of Young's Modulus to density, which would result in an optimum lateral bending frequency. Aluminum, stainless steel, and titanium were considered and studied extensively. At the end of the project, the material that looked most promising was zirconium alloy because of its high modulus-to-density ratio, good wear characteristics, and good ability to withstand the high neutron flux without damage. While the weight 


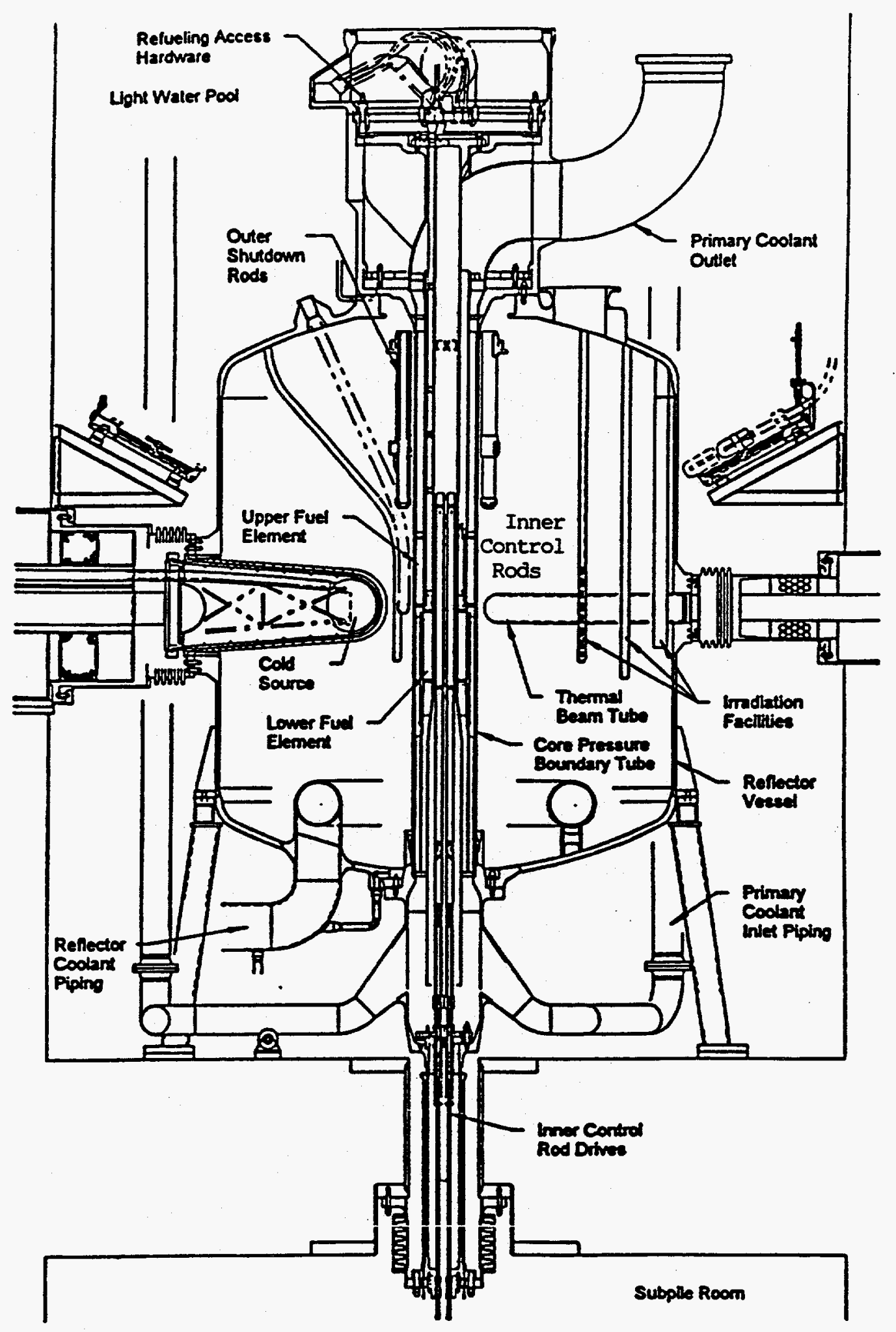

Fig. 1. Section through the Advanced Neutron Source reactor assembly. 


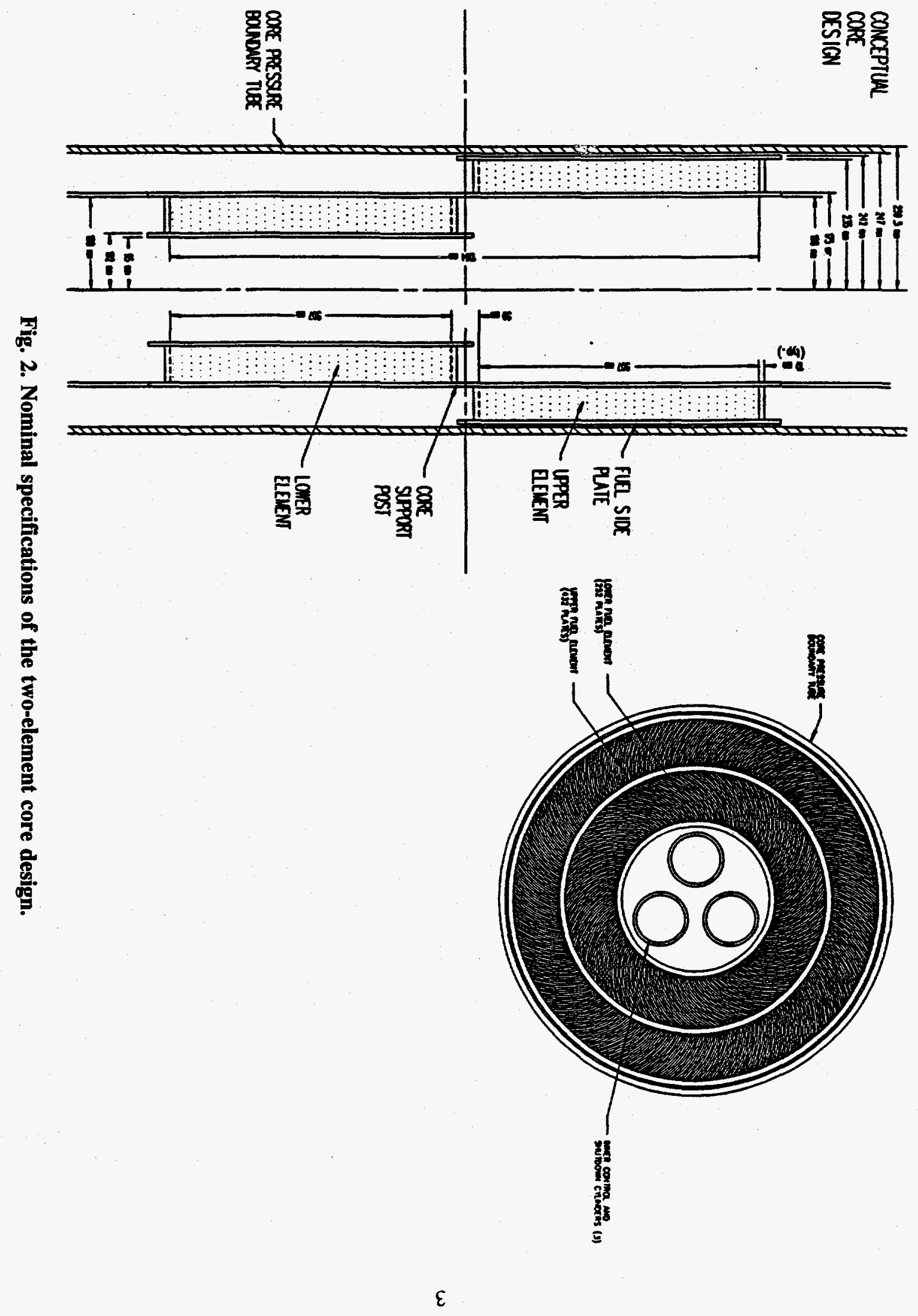


was increased, the scram requirements were reduced late in the program so that the added scram weight was sufficient that the lower acceleration values could be achieved.

In 1994, the reference core was changed from the two-element to a three-element geometry with fully overlapped upper elements, as illustrated in Fig. 3. The three-element core was selected to offer more fuel volume and thereby to provide the option of using uranium of a low enrichment. The three-element core also provided an increased thermal-hydraulic safety margin, which lowered the scram performance requirements. The final configuration of the three-element core was about $140 \mathrm{~mm}$ shorter than the previous two-element core, so the hafnium length was reduced from 1200 to $1060 \mathrm{~mm}$ on the inner control element system with the same extension beyond the cores. This reduced length made a small improvement in FIV responses and in the scram performance. While the change was small, it may have opened the possibility of going to an extract-down, scram-up configuration that would have greatly simplified the inner control element system.

In the discussion that follows, a summary is given for the FIV, buckling, and scram analyses performed on the inner control element system. The discussion in each section is loosely arranged in chronological order with emphasis on the reason for design changes based upon structural and performance requirements.

\section{FLOW-INDUCED VIBRATIONS}

In the preconceptual phase of the ANS inner control rod design, there were several unsolved problems. The four long slender rods would have been easily excited by turbulent flow to predicted amplitudes that involved severe contact with the containment cylinder and with each other. The rods were also shrouded by very tight-fitting guide cylinders. Rollers fixed to the rods rolled on the inside of each of these four small cylinders. Consequently, the unsupported length of the rods increased as the rods were extracted to reach the end of the fuel cycle. For the early conceptual studies, a finite-element model of a single rod was developed in the MSC/NASTRAN computer code ${ }^{1}$ using beams to represent the primary structure. Modal studies were performed to gain an understanding of the natural frequencies of the rods. The extremely long unsupported length resulted in a very low fundamental bending frequency $(1.5$ to $3 \mathrm{~Hz})$ of the inner rods, and consequently very high amplitudes were predicted for the FIV response. Turbulent axial flow between the rods and their respective supporting cylinders would have also been very susceptible to a fluid-elastic instability where the rods could have buckled or responded in an unstable flutter mode.

Early concepts also had the scram springs arranged such that the majority of the rod was in compression until scram was initiated. These compressive loads caused a further reduction in the lateral frequencies of the rods. Consequently, the FIV amplitude was further increased. These FIV considerations alone caused a major redesign and reevaluation of the inner control rod functional requirements. It was decided that adequate redundancy could be maintained with only three rods because the criteria stated that the scram must be completed with one rod failed. Neutronic calculations showed that this goal was achievable with the existing quantity of hafnium, so very little increase in the total weight of hafnium was needed for three rather than four rods.

The main advantage of the three-rod configuration from an FIV standpoint was that the three rods were a much larger diameter for the same containment area and that the predicted FIV amplitudes were thus greatly diminished. Larger open areas between rods were also possible, which reduced the possibility of an unstable flow pattern developing. The three tight-fitting cylinders were replaced with a bracket that held three sets of rollers to support each rod at a given distance above the upper bearing of the lower guide post, as shown schematically in Fig. 4 for the Conceptual Design Report (CDR) 


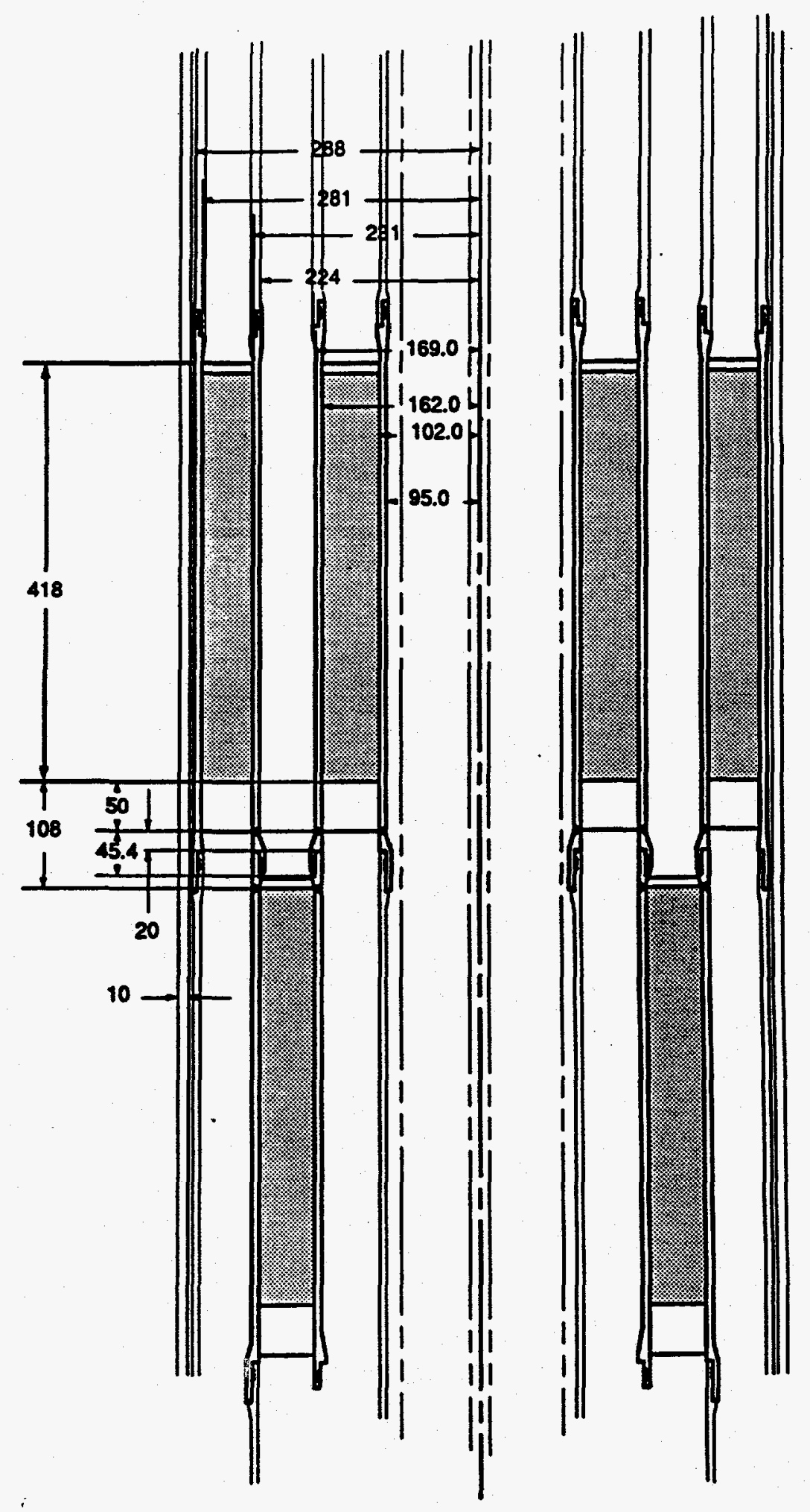

Fig. 3. Three-element core with full overlap of upper elements. 


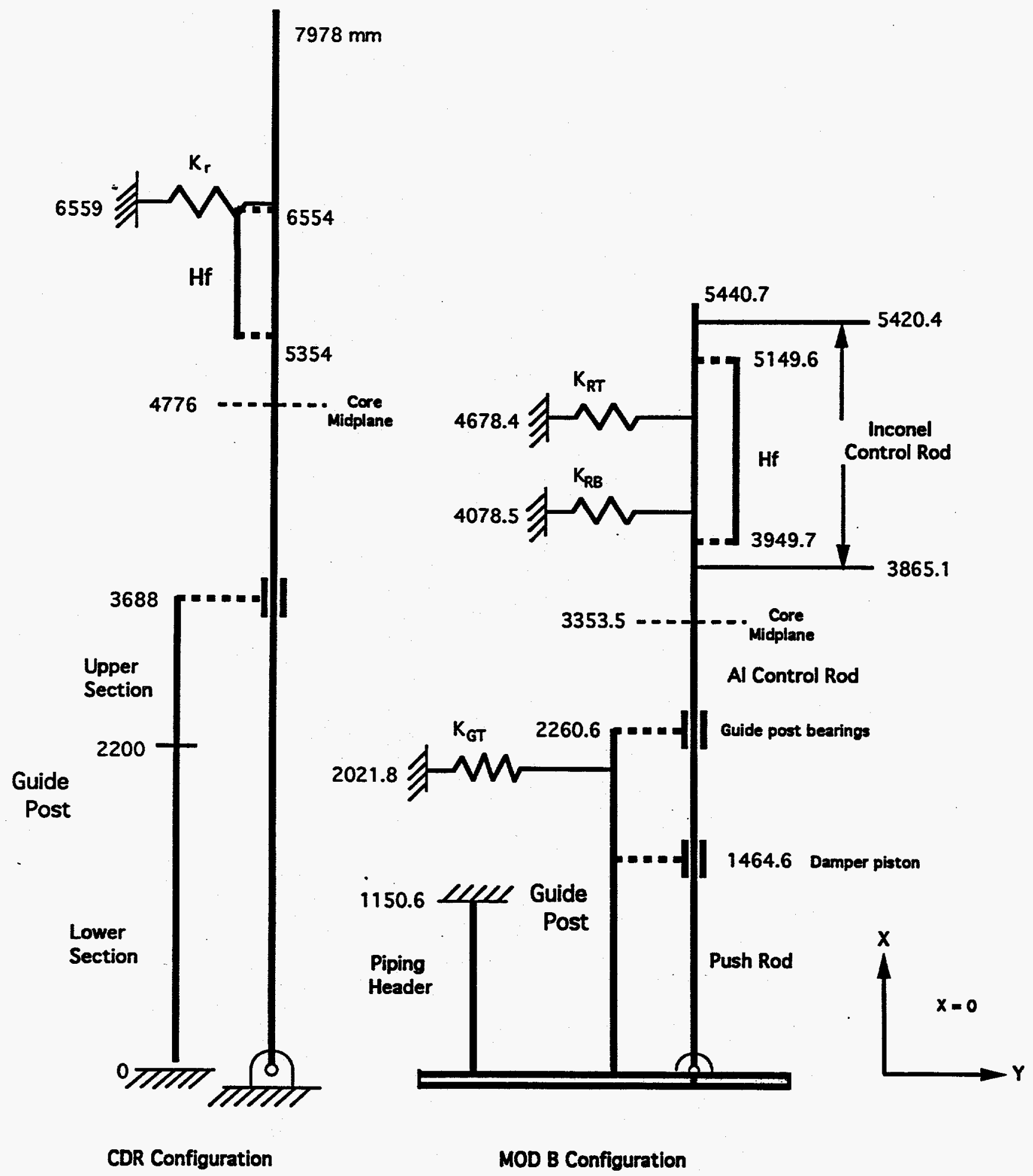

Fig. 4. Inner control element geometry at fully extracted position. 
configuration. Later in the MOD B revised configuration, a second upper set of rollers was added for additional support to each rod.

The lower set of rollers supported the rods at insertion and all positions of extraction, and the rollers were mounted on cantilevered springs attached to the bracket so that small misalignments and FIV response could be accommodated easily. The upper set of rollers contacted the rods about $100 \mathrm{~m}$ prior to the criticality extraction length of $700 \mathrm{~mm}$. The length of each of the hafnium cylinders remained constant at $1200 \mathrm{~mm}$ for the three-rod configuration because length was dictated by the length of the core. Thus, the rods were extracted about $600 \mathrm{~mm}$ before the second set of rollers provided support. This upper set of rollers was also spring mounted to prevent binding with the lower set and to provide a flexible response for the FIV amplitudes. The modal calculations indicated that equal sets of spring rates were required to keep the fundamental bending frequency above $6 \mathrm{~Hz}$ for all extraction lengths, which represented a minimum threshold value to maintain the FIV response within the allowable clearances of the modified configuration. The top set of rollers was especially important for the fully extracted configuration, where the fundamental bending frequency was a minimum.

Because the conceptual design configuration had rollers that contacted the outside diameter of the rods, there was a concern of wear on the hafnium cylinder. To avoid this problem, the hafnium cylinder was shrunk to fit within an Inconel cylinder, while holding the mass and length of the hafnium constant by increasing the hafnium wall thickness. An annulus between the hafnium and Inconel outer cylinder provided cooling flow for each component, as well as the majority of the internal flow within the hafnium cylinder. In the first concept of this configuration, the flow from the annulus exhausted into the area between the three rods near the top end of the rods. Since the annulus and associated exhaust ports had a relatively small area, there was a concern that these external ports would act as small jets and would provide a lateral oscillatory force as the rods deflected and approached the walls of the inner cylinder. The solution was to exhaust the annulus flow into the internal flow stream inside the hafnium and to enlarge the exhaust ports to reduce the jet effect from the annulus flow stream.

The lower guide post was also stiffened for the CDR configuration by the addition of material around the circumference to make an integral or single guide post rather than the three posts attached to each other at discrete points. An attempt was made to maximize the sectional area moment of inertia of the single guide post while trying to keep the mass to a minimum. The addition of material to the guide post created a potential for more heating and material damage problems. While the guide post thermal analysis was not completed to see if the mass was too large, removal of some material from the guide post would not have had a big effect on the fundamental bending frequency at the fully extracted configuration. In fact, the addition gave a disappointingly small increase in the bending frequency so that removal of some of the material would not have been a serious problem.

For most of the analyses, it was assumed that the base of the guide post was cantilevered at the bottom interface with the flow inlet support structure. Because of the complex design and assembly requirements for the guide post, the baseline interface at the bottom contained some large attachment nuts that represent a soft spot structurally and might allow some rotational flexibility about the horizontal axes. The net effect would be, as a worst case, a pinned base for the guide posts. Modal analyses showed that the fully extracted fundamental frequency dropped from 6.2 to $4.5 \mathrm{~Hz}$ with the base of the guide post pinned. While this was a lower bound, it was felt that a better attachment scheme should be devised to provide a near cantilevered interface at the guide post base. Revised concepts were not published prior to the project cancellation.

Figure 4 illustrates the dramatic differences between the CDR and MOD B configurations when positioned in the fully extracted configuration. Note that all interfaces were assumed pinned in Fig. 4, except for the base of the guide post and the piping header, which were assumed clamped. The overall length of the control rod system was shortened by $2530 \mathrm{~mm}$, driven primarily by the poor FIV 
performance of the CDR configuration. Shortening the guide post by $1427 \mathrm{~mm}$ also brought a large benefit in the increased stiffness of the guide post. It should be noted, however, that the separation distance of the scram mechanisms from the core centerline was unchanged so that radiation damage would be no greater for MOD B than for the CDR configuration. Also, as already discussed, the second major modification to the MOD B configuration is the addition of a second set of rollers and the lowering of both sets of rollers nearer to the centerline of the core. The reason for the lowering was to provide better support for the rods, and the justification for doing so was that the rollers could be replaced as often as each fuel cycle because they would have to be removed each time the core was replaced. With the above noted modifications, the fundamental bending frequency increased from $3.61 \mathrm{~Hz}$ for the CDR configuration to $6.2 \mathrm{~Hz}$ for the MOD B configuration. This increase in frequency greatly diminished the predicted FIV responses.

For both the CDR and MOD B configurations, a complete finite-element model was developed using the MSC/NASTRAN finite-element code. This three-rod model was built from beam and linear spring elements and represented the connectivity between the rods resulting from the common guide post. The hafnium was modeled as a separate cylinder (beam) that was pinned at each end of the hafnium segment, as shown schematically in Fig. 4. For the MOD B configuration, the piping header model was also included but made very little difference to the modal results. With this complete control element system modeled, the first several modes were computed, and the most important fundamental mode for the fully extracted configuration is shown in Fig. 5. ${ }^{2}$ These modes were used to make an equivalent but simplified model, as reported in Ref. 2, to be used in the evaluation of the FIVs as indicated in the discussion to follow.

To predict the FIV response of the inner control rod system, a semiempirical expression was used that was developed by Paidoussis based on measured axial flow data. ${ }^{3}$ Working with the ANS project, Paidoussis enlarged that data base with all data available through 1992 and verified once again that his equation envelopes all the data for the range of interest $(6$ to $15 \mathrm{~m} / \mathrm{s}){ }^{4}$

The FIV of major concern with the inner control rod system is subcritical in nature, so stability, either in a flutter or buckling mode, is not the primary concern. It has been shown that the dynamics of clustered cylinders in dense axially flowing fluid are remarkably different from those of a single cylinder in an infinite flow field. Experimental evidence has demonstrated the importance of hydrodynamic coupling in FIV of clusters. ${ }^{5}$ It was found that vibration occurs in prescribed intercylinder modal patterns that agree very well with those predicted by finite-element models if the added mass effect is taken into account. Gagnon computed the added mass matrix for the three-cylinder system using the section properties of the inner control rod system and outer cylinder in the region of the hafnium, which was the same for the CDR and MOD B configurations. ${ }^{6}$ The very small intercylinder gap-to-radius ratio of about 0.1 caused the added mass effect to be about 2.5 times the mass of the displaced fluid, so this mass was added as nonstructural mass (no stiffness contribution) to the finite-element model of the inner control rods. The net effect was a reduction in the fundamental frequency of about $20 \%$ from $8 \mathrm{~Hz}$ down to $6.2 \mathrm{~Hz}$ because the fluid mass is only a portion of the total structural loading.

Several researchers have shown that analytical models can be developed for the prediction of vibration of clustered cylinders that includes the intercylinder coupling effects, ${ }^{7}$ but most agree that the forcing function or pressure field is not well understood. Measurement of the pressure field in a rigid flow system is much more difficult than measuring the flexible response of the system. Upon early recommendations from Paidoussis, it was decided to use his semiempirical expression for the FIV response predictions and to plan a full-scale test to verify the FIV responses. The Control Element Test Facility (CETF) to do that full-scale testing was well along in the design phase when the program was cancelled. 

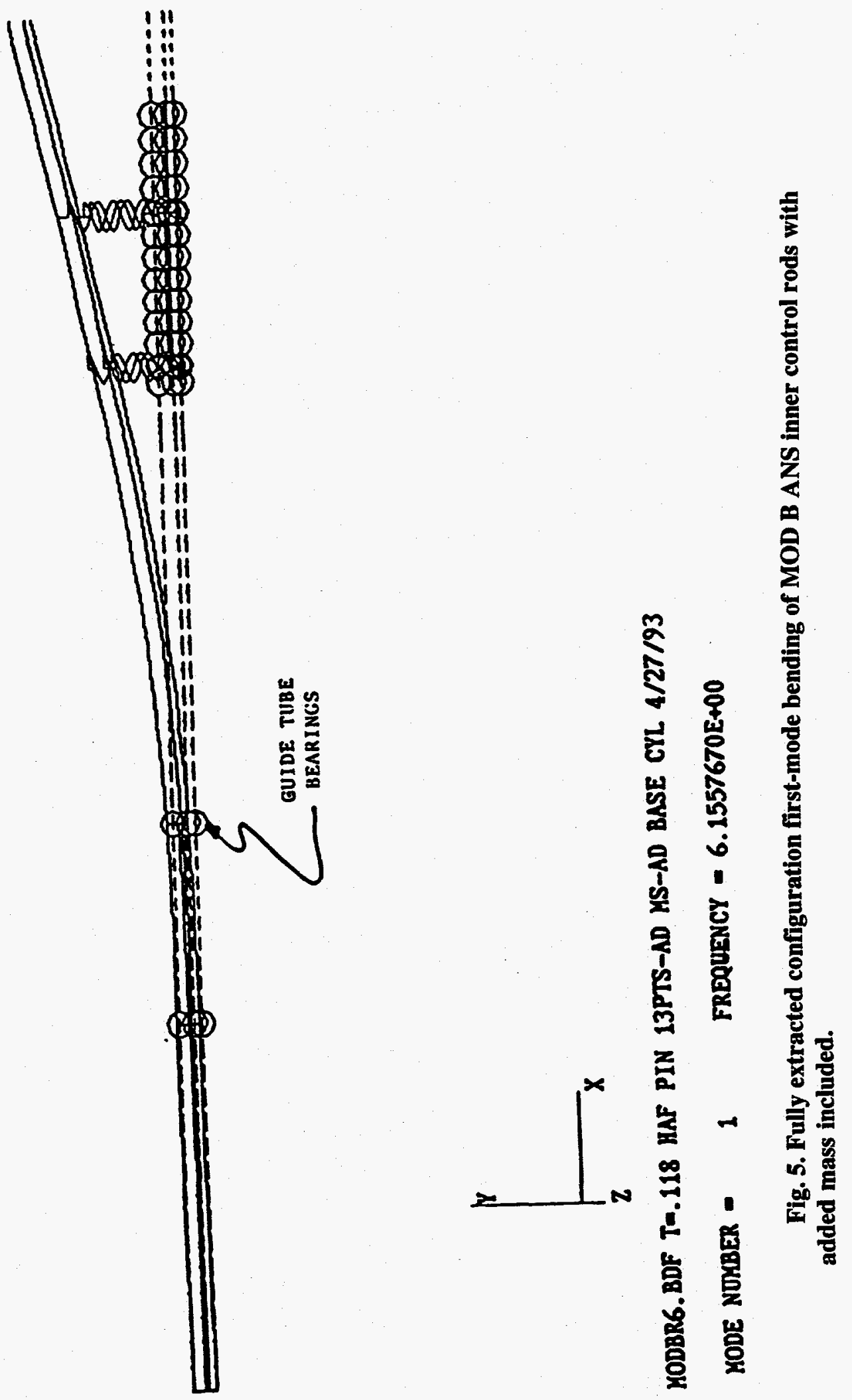
Application of the semiempirical expression to the MOD B inner control element configuration was completed in two steps. Separate analysis for flow inside and outside the elements was made, and the results were added to get the total response. For a flow velocity of $6 \mathrm{~m} / \mathrm{s}$, the response at the tip end of each rod was computed to be $2.23 \mathrm{~mm}$ because of the internal flow and $1.28 \mathrm{~mm}$ because of the external flow. The total root mean square response is the sum of these values and is equal to 3.5 $\mathrm{mm}$. To ensure that no contact is made between the elements or with the containment cylinder, a peaking factor should be included. Since little is known about the statistics of the data used to develop the semiempirical expression, it was decided to use the standard factor for Gaussian distributions of 1.414 , resulting in a peak value of $5.0 \mathrm{~mm}$ for the MOD B configuration. Thus, with a clearance of $8 \mathrm{~mm}$ between the rod and the outer cylinder wall and $19 \mathrm{~mm}$ between the control elements, there is a margin of safety. The CDR configuration response was predicted to be much larger because of a much lower fundamental natural frequency, as summarized in Table 1. The 15.8-mm CDR response was unacceptable because it greatly exceeds the minimum clearance of $8 \mathrm{~mm}$.

Table 1. MOD B configuration fully extracted response levels, using the Paidoussis semiempirical expression

\begin{tabular}{llcccc}
\hline \multicolumn{1}{c}{ Configuration } & $\begin{array}{c}\text { End } \\
\text { condition }\end{array}$ & $\begin{array}{c}\text { Length } \\
(\mathrm{m})\end{array}$ & $\begin{array}{c}\mathrm{f}_{\mathrm{n} 1}{ }^{a} \\
(\mathrm{~Hz})\end{array}$ & $\begin{array}{c}\text { Flow } \\
\text { velocity } \\
(\mathrm{m} / \mathrm{s})\end{array}$ & $\begin{array}{c}\text { Peak } \\
\text { response } \\
(\mathrm{mm})\end{array}$ \\
\hline CDR & pinned & 7.9 & 3.61 & 6 & 11.5 \\
CDR & cantilevered & 3.2 & 3.61 & 6 & 15.8 \\
MOD B & cantilevered & 3.2 & 6.2 & 6 & 5.0 \\
$\begin{array}{l}\text { MOD B with two } \\
\text { sets of top springs }\end{array}$ & cantilevered & 3.2 & 8.5 & 6 & 3.0 \\
$\begin{array}{l}\text { MOD B with } \\
\text { reduced velocity }\end{array}$ & cantilevered & 3.2 & 6.2 & 4.3 & 2.7 \\
\hline
\end{tabular}

"Fundamental natural frequency including fluid mass effects.

If we use a more optimistic estimate of the upper roller spring rates and increase them by a factor of 2 , then the fundamental frequency increases from 6.2 to $8.5 \mathrm{~Hz}$, and the peak amplitude drops to $3.0 \mathrm{~mm}$. Thus, the range of estimate for the flow-induced response is between 3 and $5 \mathrm{~mm}$ for a flow velocity of $6 \mathrm{~m} / \mathrm{s}$. Rod ejection might occur at velocities above $4.3 \mathrm{~m} / \mathrm{s}$, so the baseline response was predicted for this velocity to be about $2.7 \mathrm{~mm}$, compared to the $5.0-\mathrm{mm}$ response for $6 \mathrm{~m} / \mathrm{s}$. For these low velocities, it was found that the FIV response is roughly proportional to the square of the velocity and that any reduction in flow velocity requirements provides a more than proportionate reduction in FIV response.

After considerable study of many configurations, the fully overlapped, three-element core shown in Fig. 5 was chosen as the baseline design. As soon as this core configuration was adopted, the inner control rods finite-element model was modified to reflect the shortened version of the core. This configuration held constant the size of the reflector vessel and the core centerline. As a result of these constraints, the lower support member (guide post) was longer by $66 \mathrm{~mm}$ than the previous configuration. The hafnium length was shortened by $140 \mathrm{~mm}$, and the effective length of the fully 
inserted control rod system shortened by $70 \mathrm{~mm}$. New materials were also added to the model to reflect the change to a titanium outer cylinder and a primary rod material of zirconium alloy. The zirconium alloy wall thickness was also reduced by $1 \mathrm{~mm}$ to reduce heating. The net result of all these changes was an increase in the fundamental frequency of about $8 \%$ from 6.1 to $6.6 \mathrm{~Hz}$ for the fully extracted configuration. This small change, although in the right direction, did not eliminate the concern for FIVs. Modal studies, as a function of extraction length, were continued for the threeelement, overlapped core configuration.

For the configuration with $1060 \mathrm{~mm}$ of hafnium, the second set of rollers is contacted at an extraction distance of approximately $373 \mathrm{~mm}$. When the rods have extracted to a point just prior to contact with the second set of rollers, the fundamental frequency has dropped to $5.4 \mathrm{~Hz}$, using the baseline spring rate of $23,200 \mathrm{~N} / \mathrm{m}(133 \mathrm{lb} / \mathrm{in}$.). Table 2 shows a summary of the first and second bending modes of the control element system for a factor of 2 variation in the bottom roller spring rate with the top roller spring rate held constant at $46,400 \mathrm{~N} / \mathrm{m}(266 \mathrm{lb} / \mathrm{in}$.). Upon entering the second set of rollers, the first-mode frequency takes a step jump up to $8.30 \mathrm{~Hz}$ because of the added restraint of the top rollers. As extraction continues to the fully extracted configuration $(1060 \mathrm{~mm})$, the frequency continues to drop to $6.59 \mathrm{~Hz}$. Thus, the lower value of the bottom spring causes the $5.42 \mathrm{~Hz}$ prior to upper roller contact to be the lowest frequency during the entire extraction.

Making the two spring rates equal improved the situation at all extraction lengths and caused the fully extracted configuration to be again the minimum first-mode frequency. Since the minimum frequency was above $6 \mathrm{~Hz}$, it was recommended that the spring rates be made equal. At the fully inserted configuration, only the bottom rollers are in contact, so an increase in the spring rate dramatically influences the first-mode frequency. However, it has little effect on the second-mode frequency because the spring is located near a node in the second-mode shape. As the rods are extracted further, the first-mode frequency decreased to lower than the fully extracted configuration while the second-mode frequency actually increased because of the relocation of the piston within the guide post that imposed lateral restraint on the lower portion of the rods. Again, the equal spring rates are desirable because of the slight increase in frequency. However, the second mode is far less important to FIV because it is much less likely to be excited as a result of the general shape of the second mode.

Table 2. Effect of bottom roller spring rate on the natural frequency of the inner control rods

\begin{tabular}{|c|c|c|c|c|}
\hline \multirow{2}{*}{$\begin{array}{c}\text { Extraction } \\
\text { distance } \\
(\mathrm{mm})\end{array}$} & \multicolumn{2}{|c|}{$\begin{array}{l}\text { First mode } \\
\cdot(\mathrm{Hz})\end{array}$} & \multicolumn{2}{|c|}{$\begin{array}{l}\text { Second mode } \\
(\mathrm{Hz})\end{array}$} \\
\hline & Baseline $^{a}$ & Baseline $\times 2$ & Baseline & Baseline $\times 2$ \\
\hline 0 & 6.19 & 8.05 & 10.10 & 10.35 \\
\hline 372 & 5.42 & 6.88 & 12.7 & 12.8 \\
\hline 373 & 8.3 & 8.97 & 15.0 & 15.3 \\
\hline 1060 & 6.59 & 7.23 & 10.63 & 10.89 \\
\hline
\end{tabular}

${ }^{a}$ Baseline bottom spring rate $=23,200 \mathrm{~N} / \mathrm{m}$. Top spring rate $=46,400 \mathrm{~N} / \mathrm{m}$ for all cases. 
Consequently, the two sets of roller spring rates must be kept equal even though the threeelement core overall length is somewhat shorter and improved materials were used. With these constraints, the responses resulting from FIV would be only slightly lower than the MOD B configuration response reported in Table 1 and were thought to be acceptable values to use until the full-scale testing could begin to verify these results.

The concept of extract down and scram up had the potential to simplify greatly the control rod mounting system and to reduce greatly the possibility for any significant FIVs. The concept has several advantages, including the elimination of support structure from the center of the core during the reactor operation, but the biggest benefit is that the unsupported length of the inner control rods is greatly shortened prior to reaching criticality. When the extraction is down, then the springs and piston arrangement must be inverted so that the piston is near the top guide post bearing. The near proximity of these two support points provides a near cantilever effect on the control rods at the top of the guide post and reduces the unsupported length to only that above the top guide post bearing. Modal parameter studies showed that the fundamental mode frequency is highest when the two supports are positioned near each other to provide this clamped type arrangement. Since the layout of the new piston/spring arrangement had not been completed, a conservatively long distance $(1000 \mathrm{~mm})$ between the piston and guide post bearing was chosen. The fundamental mode shape of this configuration was essentially cantilevered from the top bearing and resulted in a natural frequency of $4.12 \mathrm{~Hz}$, compared to about $2.6 \mathrm{~Hz}$ for the MOD B configuration with the spring rates of the top supports set to zero. As the two guide post bearings were brought nearer to each other, the fundamental frequency increased to $4.4 \mathrm{~Hz}$.

Support of the guide post thus far had been cantilevered at the lowest point. The more conservative assumption of a pinned interface at the bottom and a lateral support at the reflector vessel increased the fundamental frequency of the above configuration to $5.7 \mathrm{~Hz}$ without any upper support for the rods. Consequently, stiffness of the guide post may have been more important for the extractdown, scram-up geometry than for the baseline configuration. Several options exist for improved guide post stiffness so that the preliminary evaluations of this configuration indicated that the $6-\mathrm{Hz}$ minimum could be achieved without upper supports and that, consequently, FIV would be of no concern.

\section{BUCKLING OF RODS}

Early scram requirements specified that the mechanical travel of $110 \mathrm{~mm}$ could take no more than $70 \mathrm{~ms}$. This travel response time required a peak acceleration of nearly $6 \mathrm{~g}$ 's when the properties of linear coil springs used to accelerate the rods were taken into account. Euler column-buckling calculations indicated that the early four-rod configuration was likely to buckle. With the springs acting so that the rods were in compression, there was a great concern that the long slender rods could buckle and prevent scram completion. For the CDR and revised MOD B configurations, where the rods were in tension during this acceleration, the problem of buckling became less important. The concern later switched to the deceleration segment of the stroke, where the rod came in contact with the deceleration spring. Under certain circumstances this spring could bottom out to give very high deceleration loads. The collapse of the deceleration spring could occur only during a false scram from a position near or below the latched, fully inserted configuration, so that there was no criticality concern; but even so, rod buckling was considered unacceptable. The proposed solution (although not implemented because of project cancellation) was to place a very stiff spring in series with the deceleration springs so that the peak deceleration could be limited to some large but acceptable value. Detailed buckling analyses indicated that the critical buckling load could be quite high for the shorter 
MOD B configuration so that a deceleration of more than $20 \mathrm{~g}$ 's would be acceptable. With the reduction of the scram requirements from a 100 - to a 55-mm stroke, the concern about buckling of the rods became a less important issue, and it was thought that, with the dual set of top rollers, the buckling problem was resolved for the revised MOD B configuration.

\section{SCRAM PERFORMANCE}

A detailed study of the scram performance was made for the early criteria of a $110-\mathrm{mm}$ movement in $70 \mathrm{~ms}$ because this response time is fast compared to most existing reactors. The equation of motion of a single rod was programmed for the CDR and MOD B configurations. Details of this early work and the parameters used are documented in Ref. 8. This simulation included the spring characteristics, structural and fluid inertial and friction forces, and gravity. The simulation included the steady state flow friction forces and the transient fluid forces resulting from the motion of the rods relative to the fluid. The inertial forces of the fluid trapped ahead of the piston were also included in the simulation. These inertia terms are most important at the beginning of the stroke, when the largest mass is present and the acceleration values are near their peaks.

The scram mechanism also contained a piston with a series of holes in its cylinder to provide a deceleration effect that was proportional to velocity and to act in conjunction with the springs to decelerate the rod. The hole diameters varied along the length of the cylinder to give a varying deceleration force along the stroke. However, the profile could be truly optimized for only a single scram extraction length, so some compromise was required in the damper profile. The analysis also included leakage effects in the piston/cylinder system, and these were estimated based on current tolerances and seals.

Another primary contributing force to the rod dynamics was found to be any pressure difference $(\Delta P)$ that existed across the piston because of the coolant $\left(D_{2} O\right)$ flowing past the assembly. To minimize the $\Delta \mathrm{P}$ across the piston, the outer cylinder around the control rods was extended downward to meet a seal at the lower end of the guide post support flange. The exact nature of this seal was not decided but was intended to be loose fitting and with a small amount of leakage. The end result was that the high-pressure area was restricted to be external to the cylinder so that the $\Delta \mathrm{P}$ across the piston was less than a few thousand pascals. Consequently, the scram performance could be ensured in that the fluid in front of the piston was exhausting to a low-pressure region during the scram operations.

With the CDR design modifications and the switch from an aluminum to an Inconel/zirconium alloy system baseline, the scrammed mass rose from 36 to $48 \mathrm{Kg}$. Even with this greater mass, the spring force was still adequate to meet the $110-\mathrm{mm}$ scram requirements with only two of the three rods operational. The peak scram deceleration was reduced from a maximum of $3.6 \mathrm{~g}$ 's to approximately $2.7 \mathrm{~g}$ 's by an optimization of the damper profile.

Reduction of the scram requirements to only $55 \mathrm{~mm}$ in $70 \mathrm{~ms}$ reduced the peak acceleration from nearly $6 \mathrm{~g}$ 's to less than $3 \mathrm{~g}$ 's so that acceleration, peak velocity, and peak deceleration values were much smaller and, consequently, needed less spring force to give a substantial margin to ensure an adequate shutdown. Preliminary studies were underway to simplify the acceleration and push springs to a single-spring system. This simplification would have reduced the complexity of the central region of each rod and allowed much better cooling flow through that area, as well as providing a much simpler system to build and assemble. Performance requirements could be met with a single spring system for the critical case of fully extracted rods. However, the other extraction distances had not been studied to see if the response time was adequate. The response time criteria, although reduced 
in severity, had not been fully defined for extraction distances between $600 \mathrm{~mm}$ and the fully extracted length of $1200 \mathrm{~mm}$. Consequently, the fully extracted configuration may not have controlled the spring rate parameters. That is, the performance at the fully extracted configuration could have been higher than required in order to ensure that adequate insertion force was available at the small extraction distances. However, if that issue could have been resolved, then the single spring had another big advantage in that the acceleration and deceleration forces would be much lower at the small extraction lengths of zero to $600 \mathrm{~mm}$. This fact would prolong the life of all the scram components and reduce the risk of fatigue in the rods because a scram was required each time at extraction distances less than the criticality distance to ensure proper operation. This requirement would result in a large number of scrams in the projected 2-year life of the scram system, which could cause excessive wear if the twospring system, which resulted in large accelerations, were used.

\section{CONCLUSIONS}

Although flow velocities were well below the structurally unstable flow velocity, FIVs represented a potentially serious problem for the inner control element system in the preconceptual and conceptual designs. The predicted response amplitudes indicated contact between the rods and the outer cylinder and likely contact between rods, depending on the phasing of the vibrations. The shortened version, referred to as the revised MOD B configuration, had a much higher fundamental frequency and correspondingly lower flow-induced response predictions. The MOD B configuration was considered acceptable, but all the details of coolant flow through the complex scram springs had not been settled at the time the project was terminated.

The FIV prediction for the three-element, overlapped core showed a small improvement over the MOD B configuration because of the somewhat lower overall core height. Rod ejection was considered to be resolved and FIV problems lessened because the coolant flow velocity could be kept below the critical level because of a somewhat lower heat flux on the rods for the three-element configuration and because a large $\Delta P$ resulting from a pipe break would insert rather than extract the rods for both the MOD B and three-element core configurations. The concept of extract down and scram up was examined, and it appeared that such a concept would have eliminated the FIV problem. The unsupported length is a maximum at the fully inserted position and becomes very small as the rods are extracted downward. Preliminary analyses indicated that adequate support could be provided by the guide post alone so that the upper support rollers could be eliminated. Without the upper supports, the assembly procedures would be greatly simplified. Extraction down eliminated many of the material problems encountered by the baseline configurations in that the support system is not in the central core region as the core becomes critical. The major problem with the extract down concept was that a breakage in the lower seal area or push rods would allow the $\Delta \mathrm{P}$ across the rods to extract them fully and cause a potential meltdown. This problem was not resolved prior to project termination, but ideas had been developed that could have eliminated this problem. Although this concept offered potential performance gains, it was clear that additional evaluations, including interfaces with other systems, would be necessary before it could be considered the reference design.

Buckling of the rods appeared to be a problem for the early concepts of the inner control element system because of the very large length-to-diameter ratio and because of the very severe scram requirements. The revised MOD B configuration greatly improved the length-to-diameter ratio. Relaxed scram requirements further reduced the concern for buckling. Consequently, the buckling problem was considered solved for normal operating conditions. 
The revised scram requirements appeared to be very achievable from a mechanical standpoint. The springs and dampers needed to provide the scram acceleration and deceleration could have been fit into the available space. The primary unknowns with the scram mechanism were the tolerances and reliability. All of these issues would have been addressed as part of the planned test program.

Selection of the proper tolerances to provide the proper damper profile without excessive leakage or binding would have been evaluated in the CETF. Long-term radiation damage effects on the spring components were also somewhat unknown and could have had a large impact on reliability.

\section{REFERENCES}

1. MSCANASTRAN, Version 68.1 [computer program], MacNeal-Schwendler Corporation, Los Angeles, April 1994.

2. W. R. Hendrich, “ANS Inner Control System Modal Properties," letter to M. P. Paidoussis, McGill University, Montreal, May 25, 1993, Attachment A to Attachment 9 in Monthly Progress Report for May 1993, ORNL/ANS/INT-5/V62, Martin Marietta Energy Systems, Inc., Oak Ridge Natl. Lab., June 1993.

3. M. P. Paidoussis, "The Dynamical Behavior of Cylindrical Structures in Axial Flow," Ann. Nucl. Energy 1, 83-106 (1974).

4. M. P. Paidoussis, McGill University, Montreal, letter about "proofing" the old Paidoussis semiempirical expression, to W. R. Hendrich, Oak Ridge Natl. Lab., July 19, 1993.

5. M. P. Paidoussis and J. O. Gagnon, "Experiments on Vibration of Clusters of Cylinders in Axial Flow: Modal and Spectral Characteristics," J. Sound Vib. 96, 341-52 (1984).

6. M. P. Paidoussis and J. O. Gagnon, "Added Mass Matrix-Three-Cylinder System," letter to W. R. Hendrich, Oak Ridge Natl. Lab., Nov. 21, 1992.

7. M. P. Paidoussis and L. L. Curling, "An Analytical Model for Vibration of Clusters of Flexible Cylinders in Turbulent Axial Flow," J. Sound Vib. 98, 493-517 (1985).

8. W. R. Hendrich, "Inner Control Element Scram System," Item 2 in Attachment 8 in Monthly Progress Report for February 1992, ORNL/ANS/INT-5/V47, Martin Marietta Energy Systems, Inc., Oak Ridge Natl. Lab., March 1992. 
, 


\section{INTERNAL DISTRIBUTION}

1-2. J. H. Campbell

3. S. J. Chang

4. J. M. Corum

5. W. G. Craddick

6. G. F. Flanagan

7. R. G. Gilliland

8. R. C. Gwaltney

9-13. W. R. Hendrich

14. R. O. Hussung

15-18. R. L. Johnson

19. C. R. Luttrell

20. J. A. March-Leuba
21. F. J. Peretz

22. C. C. Queen

23. D. L. Selby

24. W. F. Swinson

25. C. D. West

26. G. T. Yahr

27. ORNL Patent Office

28-29. Central Research Library Document Reference Section

30. Y-12 Technical Library

31-32. Laboratory Record Department

33. Laboratory Records, RC

\section{EXTERNAL DISTRIBUTION}

34. U.S. Department of Energy, ANS Project Office, Oak Ridge Operations Office, FEDC, MS-8218, P.O. Box 2009, Oak Ridge, TN 37831-8218

35-36. Office of Scientific and Technical Information, P.O. Box 63, Oak Ridge, TN 37831 
